\title{
ASPHYXIATING THORACIC DYSTROPHY
}

\author{
Lt Col VIPAN CHANDAR ${ }^{*}$, Lt Col AK ARORA ${ }^{*}$, \\ Col HS NAGI
}

MJAFI 1998; $54: 159-160$

KEYWORDS :

\section{Introduction}

$\mathbf{J}$ eune et al first described asphyxiating thoracic dystrophy in 2 siblings in 1954 [1]. The incidence of this rare condition has been reported to be 1 in 1,00,000 live births [2]. Scanty reports are available in Indian literature [2-5]. This condition is characterized by small constricted chest causing repeated respiratory tract infections and typical radiological appearance of thoracic cage, (long narrow bell shaped chest, short transverse ribs with bulbous ends) pelvis and long bones. It is inherited as an autosomal recessive disorder.

\section{Case Report}

Female child aged 4 years, product of a non consanguineous marriage, was admitted with history of repeated lower respiratory tract infections since early infancy. Examination revealed child having a long narrow bell shaped chest with pectus carinatum and rosary. Crown-heel length was $86 \mathrm{cms}$. upper segment; lower segment ratio 1.6:1, span $79 \mathrm{cms}$ (suggesting short limbs). Chest circumference $(30 \mathrm{cms})$ was less than head circumference $(45 \mathrm{cms})$ (Fig 1). Child had signs of severe respiratory distress with bilateral crepitations. liver $3 \mathrm{cms}$, spleen and kidneys were not palpable. Skeletal survey revealed highly placed clavicles with long narrow bell shaped chest and short transverse ribs with bulbous ends. Pelvis showed flaring of superior portions of iliac bones and a trident acetabulum (Figs 2, 3). USG abdomen and intravenous pyelogram were normal. Child was managed with intravenous fluids, broad spectrum antibiotics. oxygen and other supportive measures. She was discharged after 2 weeks and is being treated for respiratory tract infections regularly in out patient department.

\section{Discussion}

Asphyxiating thoracic dystrophy (ATD) is one manifestation of an autosomal recessive disease that involves a generalized abnormality of skeletal growth. Throacic cage abnormalities make these children vulnerable to repeated respiratory infections causing high morbidity and mortality. The characteristic radiological features include thorax with small transverse and antero-posterior diameter, short and horizontally placed ribs with bulbous ends and highly placed clav- icles. Pelvis shows flaring of superior portions of iliac bones. Most of the features were present in our case. Renal and hepatic lesions are frequently associated $[6,7]$. Respiratory distress is the cause for almost all deaths in the first year but renal abnormalities are responsible for many deaths in later life [8]. With increasing age, the respiratory problems decrease and it seems that a reasonably normal life should be possible for those few children who survive the episodes of respiratory distress and escape renal dysfunction. It has been felt that there are at least 2 forms of this condition: a mild form causes moderate respiratory distress in the new born but ceases to be a problem after a few months. These patients do not seem to develop renal disease. The majority, however, belong to severe type and die early of respiratory failure or eventually of renal failure. Renal histology shows fea-

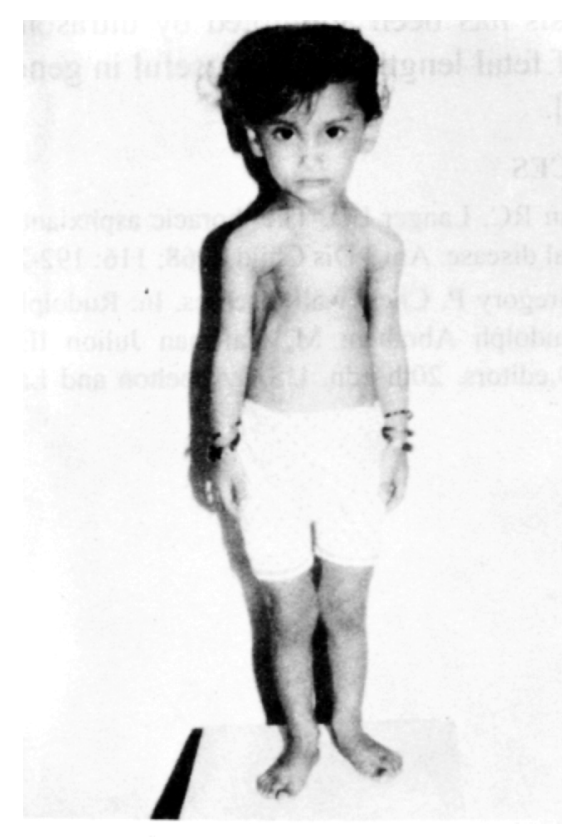

Fig. 1 : Photograph showing long narrow bell shaped chest, pectus carinatum and short limbs.

${ }^{7}$ Classified Specialist (Paediatrics), ${ }^{\#}$ Senior Advisor (Paediatrics), Command Hospital (Western Command), Chandimandir, Haryana $134107 ;{ }^{+}$Classified Specialist (Paediatrics), Military Hospital Ambala, Haryana 133001 


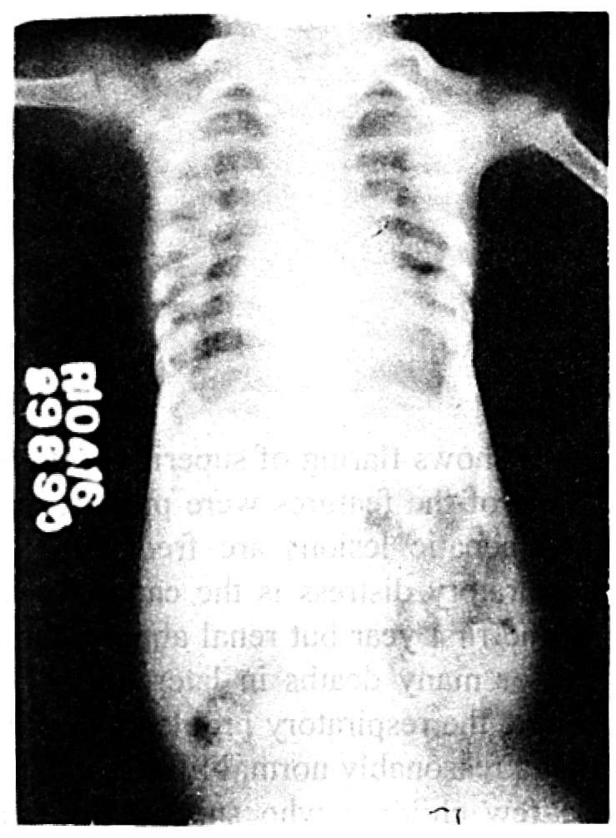

Fig. 2: X-ray chest showing high placed clavicles, long narrow chest, short horizontal ribs with bulbous ends.

tures of nephronophthisis and liver shows portal tract fibrosis and bile duct proliferation [6], lungs are hypoplastic or dysplastic.

There is no specific treatment. Surgical procedures to relieve the constriction of thoracic cage have been attempted without any encouraging results [6]. Prenatal diagnosis has been attempted by ultrasonic measurement of fetal length and it is useful in genetic engineering [9].

\section{REFERENCES}

1. Herdman RC, Langer LO. The thoracic asphxiant dystrophy and renal disease. Am J Dis Child 1968; 116: 192-201.

2. Heldt Gregory P. Chest wall diseases. In: Rudolph's Peadiatrics. Rudolph Abraham M, Haffman Julion IE, Rudolph Colin D.editors. 20th edn. USA Appelton and Lange 1996;

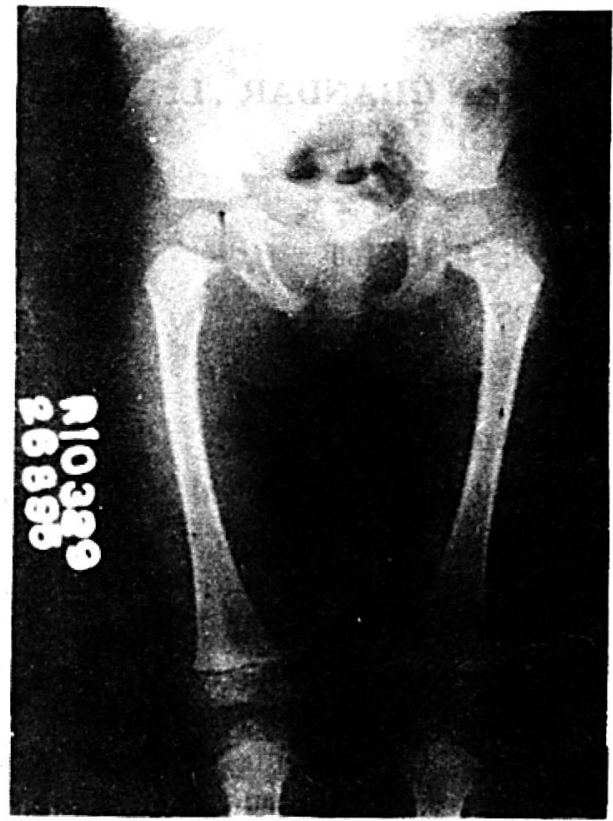

Fig. 3: X-ray pelvis showing flaring of superior portion of iliac bones, trident acetabulum and spike like protrusion at the upper end of femurs.

pp 1665-8.

3. Vatwani V, Sachdev Y. Thoracic asphyxiating dystrophy. Indian Pediatr 1986; 23: 470-3.

4. Phatak AT, Dave NA. Asphyxiating thoracic dystrophy. Indian Pediatr 1986; 23: 473-6.

5. Umakumaran P, Maiya PP, Vishwanath D. Asphyxiating thoracic dystrophy. Indian Pediatr 1995; 32: 357-9.

6. Oberk - laid F, Dantes DM, Mayne V. Campbel P. Asphyxiating thoracic dysplasia. Arch Dis Child 1977; 52: 758-65.

7. Russel JGB. Chouksey SK. Asphyxiating thoracic dystrophy. Br J Radiol 1970; 43: 814-5.

8. Tahernia AC, Stamps P. Jeune Syndrome. Clin Pediatr 1977; 16: 903-7.

9. Lipson MJ, Waskey J, Rice et al. prenatal diagnosis of asphyxiating thoracic dystrophy. Am J Med Genet 1984; 18 : 273-7. 